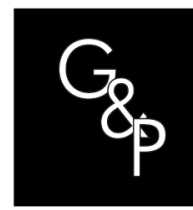

\title{
Planning the use of helicopters in the last mile distribution process in catastrophes
}

\section{Planejamento do uso de helicópteros no processo de distribuição da última milha em catástrofe}

\author{
Iran Rosa Xavier ${ }^{1}$ (), Renata Albergaria de Mello Bandeira ${ }^{1}$ (), Leandro de Oliveira Silva ${ }^{1}(\mathbb{C}$, \\ Adriano de Paula Fontainhas Bandeira ${ }^{1,2}$ (), Vânia Barcellos Gouvêa Campos ${ }^{1}$ (i), \\ Camila Maestrelli Leobons ${ }^{1}$ \begin{abstract}
Engenharia de Transportes, Rio de Janeiro, RJ, Brasil. E-mail: leandro.oliveira.sil@gmail.com
${ }^{2}$ Escola de Comando e Estado Maior de Exército - ECEME, Programa de Pós-graduação em Ciências Militares, Rio de
\end{abstract} \\ ${ }^{1}$ Instituto Militar de Engenharia -IME, Seção de Fortificação e Construção - SE/2, Programa de Pós-graduação em \\ Janeiro, RJ, Brasil
}

How to cite: Xavier, I. R., Bandeira, R. A. M., Silva, L. O., Bandeira, A. P. F., Campos, V. B. G., \& Leobons, C. L. (2021). Planning the use of helicopters in the last mile distribution process in catastrophes. Gestão \& Produção, 28(4), e5053. https://doi.org/10.1590/1806-9649-2021v28e5053

\begin{abstract}
The shortage of funding, the challenging assessment of aid needs, and the lack of transportation systems for the rescue and care of victims represent major constraints to disaster response operations. In order to improve logistical performance in these conditions, including remote and large areas, this paper proposes a formal mathematical model to assist air transport planning, using helicopters, for large-scale disasters, considering multiple deposit systems, multiples vehicles and multiple products, implemented in AIMMS to evaluate its performance. To achieve the objectives, a literature review is conducted to understand the ways in which helicopters are used in aid operations and to identify key steps in decision making and modeling processes. In the end, a hypothetical scenario is created with similar characteristics from the records of earthquake response operations that hit Haiti in $\mathbf{2 0 1 0}$ for consolidation and validation of the procedure.
\end{abstract}

Keywords: Disaster; Transportation planning; Helicopters.

Resumo: A falta de financiamento, a avaliação desafiadora das necessidades de ajuda e a falta de sistemas de transporte para resgate e atendimento às vítimas representam as principais limitações para as operações de resposta a desastres. Com o objetivo de melhorar o desempenho logístico nessas condições, incluindo áreas remotas e grandes, este trabalho propõe um modelo matemático formal para auxiliar o planejamento do transporte aéreo, por meio de helicópteros, para desastres de grande escala, considerando sistemas de depósitos múltiplos, veículos múltiplos e produtos múltiplos, implementados no AIMMS para avaliar seu desempenho. Para atingir os objetivos, uma revisão da literatura é conduzida para compreender as maneiras pelas quais os helicópteros são usados em operações de ajuda e para identificar as principais etapas na tomada de decisões e nos processos de modelagem. Ao final, é criado um cenário hipotético com características semelhantes a partir dos registros das operações de resposta aos terremotos que atingiram o Haiti em 2010 para consolidação e validação do procedimento.

Palavras-chave: Desastre; Planejamento de transporte; Helicópteros.

Received July 14, 2019 - Accepted Jan. 15, 2020

Financial support: Coordenação de Aperfeiçoamento de Pessoal de Nível Superior - Brasil (CAPES) - finnancial code 001 and CAPES Pró-Alertas 88887.091739/2014-01. 


\section{Introduction}

Disasters can be defined as sudden events that disrupt the activities of a community, causing human, material, economic or environmental losses, which exceed this community recoverability using only its own resources (IFRC, 2008). In certain situations, disasters can damage beyond the maximum recovery level or irreversibly in a vast region. These large-scale disasters are called catastrophes by Holguín-Veras et al. (2012) and they require the mobilization of transport systems and great amount of resources, from different locations, to meet several demand points in a wide area.

After a catastrophe, the transport infrastructure, such as highways, bridges and even airports, is often damaged or destroyed and, thus, transport capacity is extremely limited or non-existent (Thomas, 2003). In this scenario, managing freight transport becomes even more complex than in regular commercial logistics due to chaotic conditions. Besides, failures and delays in disaster response operations may increase human suffering. Hence, agility is crucial in this type of operation, and time becomes a critical factor in decision-making process regarding freight transport in humanitarian supply chains (Kovács \& Spens, 2012; Bandeira et al., 2011). For that reason, helicopters become the most suitable vehicle to reach victims in the first days after a catastrophe (Özdamar, 2011; Xavier et al., 2015).

However, the use of helicopters in air transport operations is expensive and managing such activities is complex. Therefore, it requires a well-structured planning-process for an efficient use of the available resources to transport supplies and human resources to the affected areas (Balcik et al., 2008; Özdamar, 2011). In a small or medium scale disaster, a helicopter can make multiple deliveries (to more than one location) at the same route, so it should be treated as a routing problem. Nevertheless, in catastrophes, helicopters usually travel from an origin to one single destination, where it delivers supplies, and return to the origin. Consequently, it can be modelled as a transportation problem, aiming to minimize the total time of service, considering multiple depots (hub), products, demand points, and heterogeneous fleet.

In this context, this paper proposes a mathematical model for planning the use of helicopters in catastrophic situations, aiming to minimize the total mission time to perform the transport in the last mile distribution to victims in isolated regions, considering aeromedical evacuations as well. The proposed model expands the restrictions found in the literature when considering: the speed of the vehicles, which has implications in the time of the service; availability of fuel and helicopters consumption; budget availability for the mission; physical compatibility between helicopters and the places that will be attended; and the possibility of the aircraft returning from the point of demand to the operational base transporting victims who need medical assistance. Finally, the proposed model is applied to a hypothetical scenario, with the characteristics of Haiti's post-disaster in 2010. The data for this application was collected on reports and interviews with members of the Brazilian Armed Forces, who served at the time in this post-disaster scenario.

Following this introduction, the paper is divided into four sections. In section 2, the main characteristics and techniques used in mathematical models, identified in the literature, to solve humanitarian supply chains' problems using helicopters are presented. Section 3 presents the proposed model, while section 4 discusses the results of its application based on the characteristics of the earthquake in Haiti in 2010. Finally, in section 5 , the conclusions, limitations and suggestions for future research are found.

\section{Literature review}

This section presents a literature review on mathematical model's applications that aim to aid decision-making in the distribution process of the humanitarian supply chain, using 
helicopters. It aims to identify the main characteristics and techniques adopted by these mathematical models identified in the literature.

A systematic literature review was developed based on the methodology proposed by Thomé et al. (2016). The search was conducted in four databases (Web of Knowledge, Science Direct, Scopus and Emerald Insight), without a time restriction, using the following groups of keywords into the title, abstract, or keywords: (1) helicopter; (2) distribution or logistic* or supply chain or last mile; (3) emergenc* or disaster* or catastroph* or extreme even* or humanitarian* or aid* or assistance ${ }^{*}$ or relief or response. The search was restricted to papers in English published in indexed international journals peer reviewed to ensure the studies quality.

Initially, 45 papers were identified. Then, titles and abstracts of these 45 publications were read in order to select only those that propose or apply optimization models to assess supply distribution by helicopters in humanitarian logistics. After this preliminary analysis, 7 of the 45 publications were eliminated because they were out of this paper topic, 15 because they did not cite the use of helicopters, 5 because they did not consider transportation of supplies and another 5 because they did not employ mathematical models. Therefore, 15 papers were selected for full reading. Of this, only 9 actually considered modeling the use of helicopters in the humanitarian chain. Finally, another 6 articles were included by the snowball process (Thomé et al., 2016), when the secondary references are consulted. A total of 17 papers were analyzed and organized by chronological order, as presented in Table 1.

Table 1 summarizes the literature review results, providing an overview of the selected papers through a comparative analysis of the methods used, the models' objective functions, restrictions, time period assessed, number of depot and characteristics of the fleet assessed.

Table 1. Papers assessed on the literature review.

\begin{tabular}{|c|c|c|c|c|c|c|c|}
\hline Paper & Data & $\begin{array}{l}\text { Objective } \\
\text { Function }\end{array}$ & Restrictions & Period & Depot & Fleet & $\begin{array}{l}\text { Resolution } \\
\text { Method }\end{array}$ \\
\hline Haghani \& Oh (1996) & Deterministics & Min OC & U / LF & Multi & Multi & Het. & Heur. \\
\hline Barbarosoğlu et al. (2002) & Stochastics & Min OC / Min TT & Un. & Mono & Multi & Het. & Heur. \\
\hline Barbarosoğlu \& Arda (2004) & Deterministics & Min OC & Un. & Multi & Multi & Het. & Exact \\
\hline Özdamar et al. (2004) & Stochastics & Min CUD & W / LF / WTW & Multi & Multi & Het. & Heur. \\
\hline Yi \& Özdamar (2007) & Stochastics & Min TT / Min OC & $\mathrm{W} / \mathrm{LF}$ & Multi & Mono & Hom. & Heur. \\
\hline De Angelis et al. (2007) & Deterministics & Max MCD & $\begin{array}{c}\text { U / TW / LF / } \\
\text { CP / MD }\end{array}$ & Multi & Multi & Het. & Exact \\
\hline OTAN (2008) - M. C1 & Stochastics & Min TT & $\begin{array}{c}\text { W / Un / LF / } \\
\text { RF }\end{array}$ & Mono & Multi & Het. & Meta Heur. \\
\hline OTAN (2008) - M. NC2 & Stochastics & Min OC & W / Un / RF & Mono & Multi & Het. & Meta Heur. \\
\hline OTAN (2008) - M. AN3 & Stochastics & $\begin{array}{l}\text { Min CUD / Min } \\
\text { TT / Max MCD }\end{array}$ & Un. & Mono & Multi & $\begin{array}{l}\text { Meta } \\
\text { Het. }\end{array}$ & Heur. \\
\hline OTAN (2008) - M. AN4 & Stochastics & Min TT / OT & Un. & Mono & Multi & Het. & Meta Heur. \\
\hline Balcik et al. (2008) & Dynamics & $\begin{array}{c}\text { Min OC / Min } \\
\text { CUD }\end{array}$ & V / WTW / LF & Multi & Mono & Het. & Heur. \\
\hline Özdamar (2011) & Deterministics & Min TT & $\begin{array}{c}\text { W / Un / LF / } \\
\text { RF }\end{array}$ & Mono & Multi & Hom. & Exact \\
\hline Berkoune et al. (2012) & Deterministics & Min TT & W / V / WTW & Mono & Multi & Het. & Heur. \\
\hline Najafi et al. (2013) & Stochastics & $\begin{array}{l}\text { Min OC / Min } \\
\text { CUD }\end{array}$ & $\mathrm{W} / \mathrm{V}$ & Multi & Multi & Het. & Otim. Rob. \\
\hline Battini et al. (2014) & Deterministics & Min OC & Un. & Multi & Multi & Het. & Exact \\
\hline Rivera et al. (2015) & Deterministics & Min TT & W/N/LF/TW & Multi & Multi & Het. & Heur. \\
\hline Liu et al. (2018) & Stochastics & MinOC & U/V/LF/WTW & Multi & & & Otim. Rob. \\
\hline
\end{tabular}

Notes: Objective Function: - Min OC: Minimize Operational Cost; Min TT: Minimize Total Time of Operation; Min CUD: Minimize Unmet Demand; OT: Other Type; Max MCD: Maximize beneficiaries. Restrictions: - U: Transported Units; V: Transported Volume: W: Transported Weight; LF: Fleet Limitation; TW: Time Window; WTW: Allowable Working Time; DCF: Fractional Delivery and Collect; CP: Parking Availability Restriction; MD: Minimal Demand; NV: Number of Travel; RF: Refueling. 
Among the modeling methods used, it is observed that deterministic processes are more employed than stochastic and dynamic processes since they tend to be simpler and require less the computational effort to obtain the optimal solution. As for the vehicle style modeled and the objective function, most papers represent the vehicles by binary variables, as vehicle type (Barbarosoğlu et al., 2002; De Angelis et al., 2007; OTAN, 2008; Berkoune et al., 2012) with the objective function seeking to minimize the total travel time (Barbarosoğlu et al., 2002; Yi \& Özdamar, 2007; OTAN, 2008; Özdamar, 2011; Berkoune et al., 2012) or to minimize the total operational cost (Barbarosoğlu et al., 2002; Barbarosoğlu \& Arda, 2004; Balcik et al., 2008; Rivera et al., 2015).

Balcik et al. (2008), Barbarosoğlu et al. (2002), Yi \& Özdamar (2007), OTAN (2008), Özdamar (2011), Berkoune et al. (2012), Najafi et al. (2013), Battini et al. (2014), Rivera et al. (2015) and Liu et al. (2018) focused their studies on modeling the last step of the supply chain, when humanitarian aid is delivered to the population affected by the disaster, that is, the last mile distribution. In turn, other models have a broader approach about the transport activities in the humanitarian supply chain (Haghani \& Oh, 1996; Barbarosoğlu \& Arda, 2004; Özdamar et al., 2004; De Angelis et al., 2007), considering the transfer operations of the products from its origins, through the various network nodes (including transshipment points) until reaching the final destination.

Barbarosoğlu \& Arda (2004), Balcik et al. (2008), Özdamar et al. (2004), De Angelis et al. (2007), Berkoune et al. (2012) and Battini et al. (2014)'s models address exclusively the supply distribution. Barbarosoğlu et al. (2002), Yi \& Özdamar (2007), OTAN (2008), Özdamar (2011), Najafi et al. (2013) and Liu et al. (2018) go further, considering the transport of the victims from the affected areas to the support bases as well and, thus, are more complex (Anaya-Arenas et al., 2014).

Most studies present models for distributions with multiple products $(75 \%)$, heterogenic fleet $(76 \%)$ and a single time window (mono-period - 62\%). For Özdamar \& Demir (2012), multi-period approach has as a disadvantage the need for previously estimating the length of the planning horizon. For a short-term planning, demands may not be fully met, while on a long-term, the computational effort to solve the problem can increase substantially.

Restrictions limiting the use of vehicles include: weight and volume capacity for passengers and/or cargo units, vehicles and staff working hours, time window for delivery, distribution time, cost, number of available vehicles, and number of units to transport.

From Table 1 ( $7^{\text {th }}$ column), we can identify the solution methods proposed by the papers analyzed, and, due to the complexity of such problems, exact, heuristic and meta heuristic methods are applied. Nonetheless, only $43.75 \%$ of the proposed models were applied to real scenarios. Hence, there is a reasonable balance between the number of applications to hypothetical situations and to real case studies. Regarding thes case studies, mostly $(71.42 \%)$ refers to response operations to large-scale disasters, especially earthquakes.

According to Balcik et al. (2008), one of the main operational decisions related to the last mile distribution is vehicles routing. However, according to Holguín-Veras et al. (2012) and Quarantelli (2000), response actions can occur in two types of situations: disasters and catastrophes (large-scale disasters). In small and medium-sized disasters, a helicopter can deliver supplies to more than one location on the same route, so the problem should be handled by a routing model. On the other hand, in catastrophic situations, the helicopter usually goes from an origin to a single destination, where it delivers supplies, and returns to the origin, so that the modeling of a transport problem, aiming to minimize the total time of service, is indicated for this scenario (Berkoune et al., 2012). 
Since the focus of this paper is the supply distribution and transport of victims in case of catastrophes, the work of Berkoune et al. (2012), among the 17 publications analyzed, is the closest to the proposed modeling. The model proposed by Berkoune et al. (2012) is formulated to solve a transport problem with social and economic constraints, often found in a real scenario, and restrictions on the distribution of aid resources from the support bases to the beneficiaries, considering limited vehicles and staff hours. It seeks to minimize the total time of service in a network with multiple deposits, multiple products, multiple points of demand, mono period and heterogeneous vehicles. Therefore, due to such characteristics and proximity to this paper's purposes, the model developed by Berkoune et al. (2012) is used as the basis for the model proposed in this paper.

We reformulate the model of Berkoune et al. (2012) to be applied in catastrophic situations, in which the quantities of supplies requested are greater than the vehicles capacity (in volume and/or weight) and the demand points are dispersed across large areas, as pointed out by Holguín-Veras et al. (2012). In addition, new characteristics and constraints are integrated into the model to better adjust the helicopter planning process to response operations, considering the following restrictions: vehicle speed, which has implications in the total mission time; aircraft consumption and the fuel availability in the operating bases; budget availability; compatibility between helicopters and their landing sites; and the possibility of the aircraft to return from the point of demand transporting victims that require assistance in the operations base. The proposed model is presented in the following section.

\section{Model for planning the use of helicopters in the last mile distribution system in catastrophes}

The proposed model aims to minimize the total service time, considering a network with multiple depots (hub), multiple products and mono period, as well as specific restrictions of helicopters availability, during large-scale disasters and aeromedical evacuations. The model is dedicated to large-scale disasters, so demand points are spread over large areas and the quantities of supplies requested are greater than the capacity of the vehicles (HolguínVeras et al., 2012). In the following section, the characteristics of the analyzed problem, the proposed mathematical model and its implementation are presented.

\subsection{Problem definition}

After a catastrophe, the affected population needs basic supplies, such as food, water, and hygine products, and medical resources. According to Balcik et al. (2008), the humanitarian distribuiton chain is composed by a primary distribution center (hub 1), located near to an airport or port to receive the required supplies and resources. From this hub 1, resources are assigned to regional distribution centers (hub 2), situated in a location with infrastructure near to the afeceted area. In Hub 2, supplies are separated, classified, stored and continuously transferred to local points of distribution (POD), as presented in Figure 1. In a humanitarian operation, this POD can be a booth, a pre-molded unit and even existing facilities, such as churches and gymnasiums (Balcik et al., 2008). Depending on the extent of the disaster, there may be more than one hub 2 with tactical and operational air support base facility. The use of helicopters allows the flows of goods, services and information in the humanitarian distribution chain after a catastrophe, providing the transportation of supplies and other resources from the hub 2 to the POD and aeromedical evacuations on the return trip. 


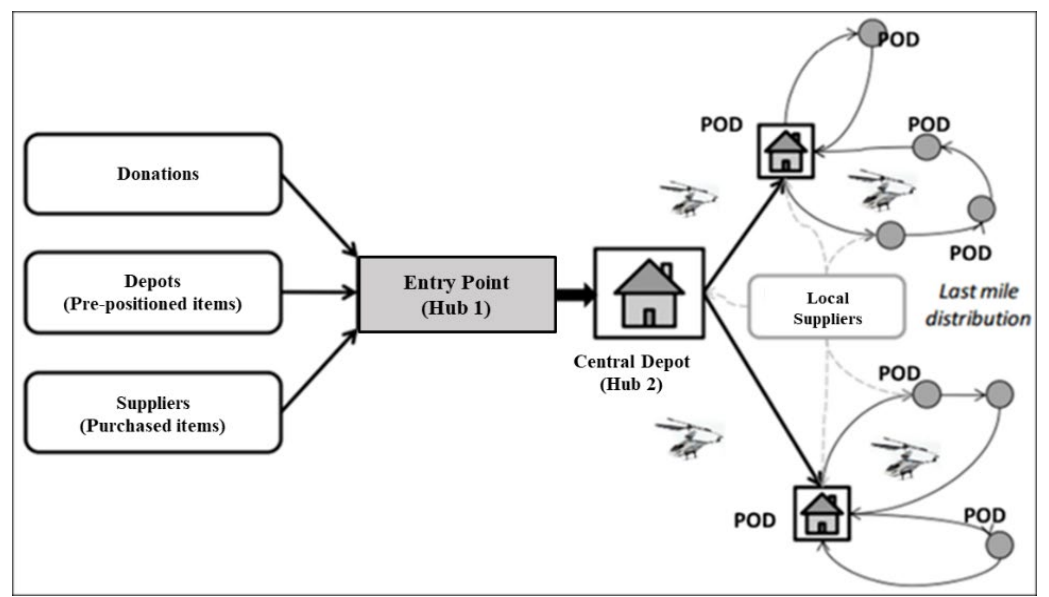

Figure 1. Physical flow of resources in the humanitarian supply chain. Source: Balcik et al. (2008).

According to the location of the available distribution centers (hub 2) and PODs, as well as to the availability of different types of aircraft, routes are determined with the purpose of minimizing the total time required to perform the transport task in the last mile distribution to victims in isolated regions, considering aeromedical evacuations as well, regarding capacity and demand constraints. Therefore, the assumptions pertinent to the proposed mathematical model include:

- a number of victims transported from POD $\mathrm{c}$ to hub $2 \mathrm{~d}$ using h-type $\mathrm{d}$ vehicles on trip number $\mathrm{v}$;

- the helicopters flight range is large enough to cover the distance between any two nodes of the supply chain network;

- at the time of application of the model, the Disaster Coordination Center estimates the quantity of supplies available and the needs of each POD;

- humanitarian aid supplies are limited and are stocked in multiple distribution centers, which are close to hub 2;

- there are different types and quantities of helicopters available at each hub 2; and

- a dedicated aircraft performs the service to a single POD, as a full load, so exclusive service missions are performed.

\subsection{Modeling}

The proposed models aims to minimize the total time required to the available helicopters to perform the transport task in the last mile distribution to victims in isolated regions, considering aeromedical evacuations as well, after a catastrophe. Therefore, the objective function is defined by analyzing the number of routes and types of vehicles used to perform the task from a number of hub 2, unloading at a specific POD and then returning to hub 2. Therefore, it is considered that the total time of aircraft operation is given by the sum of the times of displacement, cargo loading and unloading, victims' embarking and disembarking and aircraft approximation, as presented in Equation 1, which represents the model objective function.

$\operatorname{Min} Z=\sum_{d=1}^{i} \sum_{c=1}^{j} \sum_{h=1}^{m_{d}} \sum_{k=1}^{n_{d h}} \sum_{v=1}^{r} D_{d c h k v}$ 
The time required to perform each task ( $D_{\text {dckhv }}$ ), that is, the time required to make the trip v using k-aircrafts type $\mathrm{h}$ from the hub $2 \mathrm{~d}$ to meet POD $\mathrm{c}$ is calculated by Equation 2 . The definition of the sets of indices, parameters and decision variables used in the proposed model is presented in Table 2 .

$D_{d c h k v}=\left(2 \cdot T_{d c h}+\tau_{h c}\right) \cdot X_{d c k h c}+\sum_{p=1}^{a}\left(\alpha_{p h} \cdot Q T_{d c p k h v}\right)+\lambda_{h} \cdot Q E V_{d c k h v}$

Table 2. Identification of sets of indices, parameters and decision variables used in the model.

\begin{tabular}{|c|c|}
\hline Index set & Description \\
\hline $\mathrm{d}$ & set of hub 2 (distribution centers), $d=\{1,2, \ldots, i\}$ \\
\hline $\mathrm{C}$ & set of POD, $c=\{1,2, \ldots, j\}$ \\
\hline $\mathrm{p}$ & Set of supply types for humanitarian aid, $p=\{1,2, \ldots, a\}$ \\
\hline $\mathrm{h}$ & set of vehicle types, $h=\left\{1,2, \ldots, m_{d}\right\}$ \\
\hline k & set of vehicles type $h$ available, $k=\left\{1,2, \ldots n_{d h}\right\}$ \\
\hline $\mathrm{v}$ & set of trips made on the assessed day, $v=\{1,2, \ldots, r\}$ \\
\hline & Variables sets \\
\hline$X_{d c k h c}$ & $\begin{array}{l}\text { decision variable; defined as } 1 \text { if the delivery of hub } 2(\mathrm{~d}) \text { to PODc occurs } \\
\text { using the k-th vehicle type } \mathrm{h} \text { in trip number } \mathrm{v} ; 0 \text { if it occurs otherwise }\end{array}$ \\
\hline $\mathrm{QT}_{\mathrm{dcpkhv}}$ & $\begin{array}{l}\text { quantity of supplies } p \text { transported from hub } 2(d) \text { to the PODc by the k-th } \\
\text { vehicle type } h \text { in trip number } v\end{array}$ \\
\hline QEVAC $_{\text {dckhv }}$ & $\begin{array}{l}\text { number of victims transported from POD } c \text { to hub2 } d \text { using } k \text {-th vehicle type } h \\
\text { in trip number } v\end{array}$ \\
\hline & Parameters sets \\
\hline $\mathrm{DEM}_{\mathrm{cp}}$ & quantity of supplies $p$ required at the POD $c$, in units \\
\hline $\mathrm{NVR}_{\mathrm{c}}$ & number of victims to be transported from PODc, in units \\
\hline $\mathrm{ZPH}_{\mathrm{c}}$ & conditions of the landing zone at the PODc, where $\{1,2,3,4\}$ \\
\hline DISP $_{\mathrm{dp}}$ & availability of supplies type $p$ in hub $2 d$, in units \\
\hline $\mathrm{COORD}_{\mathrm{d}}$ & co-ordinates of hub $2 \mathrm{~d}$ \\
\hline $\mathrm{COORD}_{\mathrm{c}}$ & co-ordinates of POD c \\
\hline $\mathrm{DIST}_{\mathrm{dc}}$ & distance between hub $2 \mathrm{~d}$ and PODc, in $\mathrm{km}$ \\
\hline $\mathrm{T}_{\mathrm{dch}}$ & travel time between hub $2 \mathrm{~d}$ the POD c using vehicle type $\mathrm{h}$, in hours \\
\hline$P U_{p}$ & volume of a unit of supply $\mathrm{p}$, in $\mathrm{kg}$ \\
\hline $\mathrm{VU}_{\mathrm{p}}$ & volume of a unit of supply $p$, in $\mathrm{m}^{3}$ \\
\hline $\mathrm{CAT}_{\mathrm{h}}$ & category of vehicle type $h$, in $\{1,2,3\}$ \\
\hline $\mathrm{VEL}_{\mathrm{h}}$ & cruising speed of vehicle type $\mathrm{h}$, in $\mathrm{km} / \mathrm{h}$ \\
\hline $\mathrm{CAPW}_{\mathrm{h}}$ & transport capacity for vehicle type $\mathrm{h}$, in tonnes \\
\hline $\mathrm{CAPV}_{\mathrm{h}}$ & transport capacity for vehicle type $\mathrm{h}$, in $\mathrm{m}^{3}$ \\
\hline CAPPAX $_{h}$ & transport capacity of people of vehicle type $\mathrm{h}$, in units \\
\hline $\mathrm{CTHV}_{\mathrm{h}}$ & cost of one hour of flight of vehicle type $\mathrm{h}$, in monetary unit \\
\hline$\alpha_{\mathrm{ph}}$ & time for loading/unloading a unit of supply o in a vehicle type $h$, in hours/unit \\
\hline $\mathrm{T}_{\mathrm{hc}}$ & approach time of vehicle type $\mathrm{h}$ at PODc, in hours/unit \\
\hline$\lambda_{\mathrm{h}}$ & time for embark/disembark of victims in a vehicle type $h$, in hours/unit \\
\hline $\mathrm{MJ}_{\mathrm{h}}$ & maximum daily journey for each $k$-th vehicle type $h$, in hours \\
\hline $\mathrm{CCOMB}_{\mathrm{h}}$ & fuel consumption for each vehicle type h, in liters/hour \\
\hline $\mathrm{DCMB}_{\mathrm{d}}$ & availability of fuel in the hub $2 d$, in liters \\
\hline $\mathrm{MHVD}_{\mathrm{h}}$ & maximum availability of flight hours for vehicles type $h$ \\
\hline ORC & maximum budget availability for air operation, in monetary units \\
\hline
\end{tabular}


The set of constraints were defined as:

a) supply limitation of products (supplies) $p$ to the availability of each product type, as presented in Equation 3.;

$\sum_{c} \sum_{k} \sum_{h} \sum_{v} Q T_{d c p k h v} \leq D I S P_{d p}, \quad \forall d, p$

b) guarantee the supply of the demand for products $p$ at POD $c$, as presented in Equation 4.;

$\sum_{d} \sum_{k} \sum_{h} \sum_{v} Q T_{d c p k h v} \geq D E M_{c p}, \quad \forall c, p$

c) guaranteeing that trip $(v)$ respects weight limit, as presented in Equation 5.;

$\sum_{p} P U_{p} \cdot Q T_{d c p k h v} \leq C A P W_{h} \cdot X_{d c k h v}, \quad \forall d, c, k, h, v$

d) guaranteeing that trip ( $v$ ) made with vehicle type $(h)$ leaves hub $2(d)$ for POD (c), as presented in Equation 6.;

$\sum_{d} \sum_{c} \sum_{k} \sum_{h} X_{d c k h v}=1, \quad \forall v$

e) guaranteeing that, for each trip $(v)$, the volume limit carried by vehicle type $(h)$ is respected, as presented in Equation 7.;

$\sum_{p} V U_{p} \cdot Q T_{d c p k h v} \leq C A P V_{h} . X_{d c k h v}, \quad \forall d, c, k, h, v$

f) ensuring that the victims that required aeromedical evacuation for medical purposes are transported, as presented in Equation 8.;

$\sum_{d} \sum_{k} \sum_{h} \sum_{v} Q E V A C_{d c k h v}=N R V_{c} \quad \forall c$

g) guaranteeing that, for each trip ( $v$ ), the limit of passengers carried by vehicle type $\mathrm{h}$ is respected, as presented in Equation 9.;

$\operatorname{QEVAC}_{d c k h v} \leq \mathrm{CAPPAX}_{h} \cdot X_{d c k h v}, \forall d, c, k, h, v$ 
h) guaranteeing that the vehicles landing in each POD are compatible with the characteristics of the helicopters landing area (ZPH), as presented in Equation 10.;

$C A T_{h} \cdot X_{d c h k v} \leq Z P H_{c}, \quad \forall d, k, h, v$

i) guaranteeing that vehicles have their maximum working day respected, as presented in Equation 11.;

$\sum_{c} \sum_{v} D_{d c h k v} \leq M J_{h}, \quad \forall d, k, h$

j) guaranteeing that the fuel limit available on hub 2 is respected, as presented in Equation 12.;

$\sum_{c} \sum_{k} \sum_{h} \sum_{v} \operatorname{CCOMB}_{h} \cdot\left(2 \cdot T_{d c h}+\tau_{h c}\right) \cdot X_{d c k h v} \leq \operatorname{DCOMB}_{d}, \quad \forall d$

k) guaranteeing that the budget limit is respected, as presented in Equation 13.;

$\sum_{d} \sum_{c} \sum_{k} \sum_{h} \sum_{v} C L H V_{h} \cdot\left(2 \cdot T_{d c h}+\tau_{h c}\right) \cdot X_{d c k h v} \leq O R C$

I) statement that $X_{d c k h v}$ is a binary variable as presented in Equation 14.;

$X_{d c k h v} \in\{0,1\}, \quad \forall d, c, k, h, v$

m) statement that $Q T_{\text {dppkhv }}$ is a non-negative real variable $\left(R^{+}\right)$, as presented in Equation 15.;

$Q T_{d c p k h v} \in R^{+}, \quad \forall d, c, k, h, v$

n) statement that $Q E V A C_{d c p k h v}$ is a non-negative integer variable $\left(Z^{+}\right)$as presented in Equation 16;

$Q V V A C_{d c p k h v} \in Z^{+}, \quad \forall d, c, k, h, v$

\subsection{Modeling implementation and solution}

For the solution of the model described in section 3.2, an algorithm was developed in Paragon Decision Technology's AIMMS (Advanced Integral Multidimensional Modeling Software), version 4.8.3.332, using mixed integer linear programming (PLIM). 
AIMMS enables a comprehensive visualization of the problem in a set of graphical interfaces, being able to specify and solve optimization models with linear and non-linear constraints (Ignácio \&Ferreira, 2004). The optimization model can be effortlessly transferred to the Excel solver and solved by tools such as CPLEX, XA, CONOPT and XPRESS (Bisschop, 2012). For these reasons, AIMMS was chosen as a tool to implement the proposed modeling. The model was run on a notebook with an Intel Core i5-4200U processor with $2.3 \mathrm{Ghz}$ and $6 \mathrm{~GB}$ of RAM. The following section presents the application of the proposed model to the conditions of the catastrophe after the earthquakes in Port-au-Prince, Haiti, in 2010.

\section{Application of the model based on the characteristics of the earthquake in Port-au-Prince me 2010}

This section presents the application of the proposed mathematical model to assist the planning of the use of helicopters in disaster-response operations in a scenario similar to the reality faced after the earthquake in Port-au-Prince, Haiti, 2010. We chose this event as the basis to develop the scenario to the application because it is considered the worst natural disaster in modern history, with more than 2 million people affected, 300,000 injured and 230,000 deaths (Guha-Sapir et al., 2011). In addition, this region is highly vulnerable to disasters, with continually monitored municipalities and major threats of damage caused by weather events. The data and information for the development of this analysis were collected based on reports and interviews with Brazilian military officers, who participated in the 2010 mission. In this section, it is presented the scenario in the post-disaster of Haiti in 2010, the characterization and parameterization of the model, as well as the solution to these application.

\subsection{Haiti, 2010, pos-disaster scenario}

The Haiti earthquake, on 12 January 2010, was a catastrophic event of magnitude 7.0, which had its epicentre in the eastern part of the Tiburon peninsula, about $25 \mathrm{~km}$ from the Haitian capital. Humanitarian assistance and disaster relief were initiated immediately by international organizations after the emergency alert.

During the first 24 hours after the 2010 earthquake in Haiti, the United States Coast Guard (USGC), the US Armed Forces and the United States Agency for International Development (USAID) began the process of distressing and protecting the country, which received aid from more than 140 countries and 1,000 non-governmental organizations (NGOs) in the response operation with field hospitals, troops, military aircraft, hospital ships, cargo ships, port handling equipment and helicopters (Clementson \& Fisher, 2011).

Due to the magnitude of the disaster, in the first few days after the establishment of the unified response operation, engineering teams worked on clearing and retrieving roads' access to accelerate the distribution of supplies and medical resources to victims by land vehicles. After clearing the roads, the aircraft previously destined to the distribution of supplies were dedicated only to the transportation of aid teams and aeromedical evacuations. Many helicopters were prioritized to transport patients from the affected areas to hospital care facilities, as several people were injured due to earthquake collapses, and several aeromedical evacuation missions were required (Clementson \& Fisher, 2011). At the peak of the military response, on January 31, 2010, the JTF-Haiti task force employed more than 22,200 employees, 33 U.S. Navy and USCG vessels, and more than 300 aircrafts. The JTF-Haiti task force defined that the Guantanamo bay in Cuba would be the basis of its hub-and-spoken distribution network for sending supplies to Haiti. Thus, all supplies were received at the Guantanamo airfield (GTMO), then unloaded, classified, and subsequently transported to the demand points. The U.S. operation used, in 
addition to the GTMO airfield, 40 improvised landing zones and three maritime bases, including the ships USS Carl Vinson, USS Nassau, and USS Bataan. It is noteworthy that, before the earthquake, Port-au-Prince international airport had 50 daily movements of aircrafts (light planes, helicopters, MINUSTAH and international carriers). However, at the peak of the response operation, the airfield reached more than 500 daily movements (Clementson \& Fisher, 2011).

In the first two weeks of the response operation in Haiti, aerial vehicles moved more than 8,100 people and 1,315 tons of cargo (Clementson \& Fisher, 2011). Considering the helicopters fleet used by several organizations in the earthquake response in Haiti, it is highlighted the use of the following helicopters models: $\mathrm{CH}-46$ Sea Knight, $\mathrm{CH}-53$ Sea Stallion, MV-22 Osprey, UH-1H Huey, UH-60 Black Hawk. In total, more than 1,000 flight hours were accounted for the transport of more than 500 tons of supplies and the evacuation of more than 435 clinical patients. Prior to the earthquake, Haiti's population had limited access to potable water, and this situation got worse after the event. According to the UN data, in 21 days the water treatment and distribution teams were able to set up 14 demand points and refugee camps (Holguín-Veras et al., 2012), sending helicopters to launch supplies for the fields. However, this strategy was criticized for not being a form worthy of humanitarian aid and led to violent disputes for supplies, in a way that the strongest were always benefited to the detriment of women and children (HolguínVeras et al., 2012).

\subsection{Characterization and parameterization}

After a catastrophe, large amounts of resources need to be mobilized. Holguín-Veras et al. (2012) suggest a factor between $15 \mathrm{~kg}$ and $80 \mathrm{~kg}$ of resources to be mobilized per person per day within the devastated region. In the case of Haiti, the Holguín-Veras et al. (2012) proposal was adopted as reference information, using a factor of $15 \mathrm{~kg}$ per person per day to the two million residents of Port-au-Prince, requiring thus a total of 30 thousand tons of supplies (or 1,500 loaded semi-trailers) per day to be distributed in an area of $90 \mathrm{~km}^{2}$ of difficult access.

For the case study, the locations of primary distribution centers (hub 1) and regional distribution centers (hub 2), as well as the location of the demand points, were randomly generated, using a uniform distribution in a range between $10 \mathrm{~km}$ and $80 \mathrm{~km}$ away from Port-au-Prince. For each demand point, the demands for two types of products were randomly generated using a normal distribution, with mean and standard deviation detailed in Table 3, considering Holguín-Veras et al. (2012) as reference. Each unit of product demanded has a weight and volume, respectively, associated with a loading time (in seconds) according to the type of aircraft.

Table 3. Parameters for product demand generation.

\begin{tabular}{|c|c|c|c|c|c|c|c|c|}
\hline \multirow{2}{*}{ Product } & \multicolumn{2}{|c|}{$\begin{array}{c}\text { Demand - POD } \\
\text { (uniform } \\
\text { distribution) }\end{array}$} & \multirow{2}{*}{$\begin{array}{l}\text { Wieght } \\
\text { (kg) }\end{array}$} & \multirow{2}{*}{$\begin{array}{c}\text { Volume } \\
\left(\mathrm{m}^{3}\right)\end{array}$} & \multicolumn{4}{|c|}{ Loading time per product (seconds/unit) } \\
\hline & $\boldsymbol{\mu}$ & $\sigma$ & & & Aircraft 1 & Aircraft 2 & Aircraft 3 & Aircraft 4 \\
\hline P1 & 80 & 30 & 20 & 0,027 & 15 & 15 & 16 & 20 \\
\hline P2 & 100 & 20 & 9 & 0,009 & 10 & 12 & 12 & 15 \\
\hline
\end{tabular}

From the definition of product demand (Table 3), the total capacity of hub 2 for each product was randomly generated, applying a factor between $120 \%$ and $150 \%$ in demand, in order to ensure that the demand is met. 
Regarding the transfer of victims from the affected areas (destination) to hub 2 (origin), the demand for transport is considered to be random with a uniform distribution between 3 and 22 passengers, which correspond to the aircraft passenger capacity considered in this application (Table 4). Embarkation/disembarkation time for each passenger was estimated by type of aircraft, being: Aircraft 1, referring to the model AS350; Aircraft 2, the model Bell Huey H1; Aircraft 3, the model UH-60; and aircraft 4, the model AS332. The physical characteristics of each aircraft are presented in Figure 2.

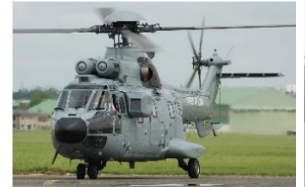

(a)

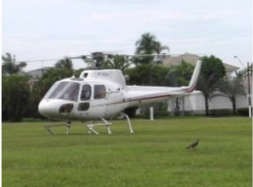

(b)

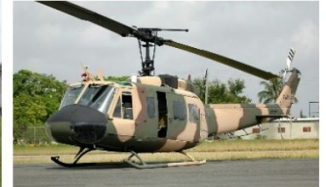

(c)

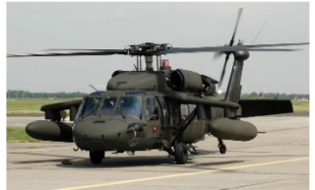

(d)

Figure 2. Aircrafts images - AS332 (a), AS350 (b), Bell Huey H1 (c) and UH-60 (d).

From the interviews with officers from the Brazilian Air Force and the official manuals, the characteristics of weight, volume, maximum daily working hours allowed (MJT), approximation time of the aircraft type $h$ in POD $c$ (Thc), passenger capacity of vehicle Type $h$ (CAPPAX), time of embarkation/disembarkation of victims, unloading of a unit of the product $p$ in a vehicle type $h\left(\lambda_{h}\right)$, speed and fuel consumption of vehicle type $h$ (CComb) of each aircraft were collected and parameterized in Table 4.

Table 4. Parameters for each aircraft.

\begin{tabular}{ccccccccc}
\hline $\begin{array}{c}\text { Aircraft } \\
\text { (helicopters) }\end{array}$ & $\begin{array}{c}\text { Weight } \\
(\mathbf{k g})\end{array}$ & $\begin{array}{c}\text { Volume } \\
\left(\mathbf{m}^{\mathbf{3}}\right)\end{array}$ & $\begin{array}{c}\text { MJT } \\
(\mathbf{m i n})\end{array}$ & $\begin{array}{c}\text { Thc } \\
(\mathbf{m i n})\end{array}$ & $\begin{array}{c}\text { CAPPAX } \\
(\mathbf{u n d})\end{array}$ & $\boldsymbol{\lambda}_{\mathbf{h}}$ (min/und) & $\begin{array}{c}\text { Speed } \\
(\mathbf{k m} / \mathbf{h})\end{array}$ & $\begin{array}{c}\text { CComb } \\
(\mathbf{k g} / \mathbf{h})\end{array}$ \\
\hline Aircraft 1 & 400 & 3 & 720 & 2 & 3 & 1 & 235 \\
\hline Aircraft 2 & 1800 & 6 & 720 & 2 & 10 & 0.8 & 205 & 275 \\
\hline Aircraft 3 & 2000 & 8 & 720 & 2 & 12 & 0.667 & 280 & 440 \\
\hline Aircraft 4 & 2200 & 9 & 720 & 2 & 22 & 0.545 & 260 & 490 \\
\hline
\end{tabular}

In summary, the model AS350 is a common aircraft with a transport capacity of 4.3 tons; the Bell Huey $\mathrm{H} 1$ is a military, multi-purpose and mid-sized aircraft designed for search and rescue missions with a capacity to carry up to 13 people and 4.3 tons of cargo; the UH60 model is used in extreme conditions and with a capacity to carry up to 14 passengers; the AS332 model has a high capacity, it can carry 25 combatants or six injured on stretchers and 10 more passengers and lift 4.5 tons; the EC725 is an aircraft applied to multiple long-distance tactical transport missions, aeromedical evacuation, logistical support, search and rescue, and capable of carrying 3.8 tons and 29 passengers or up to 11 stretchers and seats can be install for a medical team of four people.

For the model application, two hubs 2 ( $A$ and $B$ ) were pre-defined, as well as the respective number of aircrafts. Table 5 shows the number of aircrafts allocated for each hub 2.

Table 5. Quantity of aircrafts assign to each hub 2.

\begin{tabular}{ccc}
\hline Aircraft (helicopters) & hub 2-A & hub 2-B \\
\hline Aircraft 1 & 6 & 6 \\
\hline Aircraft 2 & 2 & 2 \\
\hline Aircraft 3 & 2 & 2 \\
\hline Aircraft 4 & 4 & 4 \\
\hline
\end{tabular}




\subsection{Solution implementation}

The algorithm proposed in section 3.2 was modelled in the AIMMS software and solved by CPLEX 12.6.2, considering the characteristics and parameters presented in Section 4.1. In this step, the CPLEX 12.6.2 is used so that the model is solved faster (in a few seconds) in a disaster response operation. However, to evaluate the capabilities of CPLEX 12.6.2, three scenarios were created, consisting of two deposits (hub 2) and a number of demand points (POD) ranging from 20, 40 and 60 . For each situation, 10 simulations were run. The results for the three situations are presented in Table 6.

Tabela 6. Mean results of the simulations for the number of demand points.

\begin{tabular}{rcccc}
\hline & Number of POD & $\mathbf{2 0}$ & $\mathbf{4 0}$ & $\mathbf{6 0}$ \\
\hline & Number of variables & 29210 & 58410 & 87610 \\
\hline & Number of restrictions & 29577 & 58837 & 88097 \\
\hline Average processing time (seconds) & 62.70 & 223.61 & $>3599$ \\
\hline Average load carried (kg) & 34458 & 70499 & 103910 \\
\hline \multirow{2}{*}{ Average number of people transported (pax) } & 242 & 487 & 778 \\
\hline \multirow{2}{*}{60 seconds } & Gap \% & 0.36 & 0.84 & 1.79 \\
\cline { 2 - 5 } & Optimal solution & 9 & 3 & 0 \\
\hline \multirow{2}{*}{120 seconds } & Gap \% & 0.36 & 0.53 & 0.92 \\
\cline { 2 - 5 } & Optimal solution & 9 & 9 & 0 \\
\hline \multirow{2}{*}{600 seconds } & Gap \% & 0 & 0.41 & 0.75 \\
\cline { 2 - 5 } & Optimal solution & 10 & 9 & 0 \\
\hline
\end{tabular}

Table 6 presents the average of the results obtained for the ten simulation run for each situation. It is possible to observe, from Table 6, that, for two deposits and 20 points of demand, there we no major complications to obtain the optimum solution: we were able to find 9 optimal solutions, out of 10 different simulations, in less than 60 seconds. On the other hand, for instances with 40 points, optimal solutions were obtained for only three of the 10 simulated scenarios, in less than 60 seconds of processing. Optimal solutions for six other scenarios could be defined after more than 600 seconds of processing. Moreover, for instances with 60 demand points, it was not possible to obtain any optimal solution, for the 10 different simulations, in less than 600 seconds, and most solutions of these instances only reached optimal value after processing for periods longer than 1 hour.

\section{Conclusion}

This paper proposed a mathematical model to assist in the decision making-process regarding the use of helicopters for air transport activities in response operations to largescale natural disasters (catastrophes), aiming to minimize the total time of the supply distribution operation.

Initially, a literature review was conducted in order to identify mathematical models previously proposed to address the decision-making process regarding the use of helicopters in the humanitarian supply chain distribution. Through this analysis, we could verify the limited number of studies on the distribution of humanitarian aids that consider the use of helicopters, this being a complex problem that lacks more attention by the academics. Moreover, it was identified that routing models provide subsidies for decision-making in small and medium-sized disasters situations. On the other hand, in catastrophes, large 
areas are completely destroyed and enormous amounts of humanitarian aid are needed. Therefore, full loads and dedicated vehicles are usually considered for this type of distribution process, with the vehicle transporting supplies to a single demand point. These exclusive service missions can be modeled as a transport problem.

The proposed model was characterized as a transport problem considering multiple deposits, multiple points of demand, multiple products and with heterogeneous fleet, aiming to minimize the total time of aircraft in operation, considering the following restrictions: vehicle speed restrictions, which has implications in the time of the service; the fuel consumption by each type of helicopter used and the availability of fuel in the distribution center regional (hub); budget availability for the assistance; the compatibility between the helicopters and the characteristics of the helicopter landing area (ZPH) in each point of distribution; and the possibility of the aircraft returning from the POD, transporting victims who need treatment in the hub. This paper demonstrated that adding these restrictions to the model improves the logistic planning for helicopters in response operations.

Furthermore, the proposed model was applied to a real catastrophe scenario with the intention of verifying its applicability and validation. However, by incorporating the various characteristics and restrictions pertinent to helicopter operations in the proposed model, the complexity of the model and, consequently, the computational effort to obtain the optimum solution increased. It is observed that using AIMMS/CPLEX, it was possible to obtain optimal results for small academic instances, but for a larger transport network, it is suggested that heuristic methods should be applied to achieve good results within an acceptable processing time.

\section{References}

Anaya-Arenas, A. M., Renaud, J., \& Ruiz, A. (2014). Relief distribution networks: a systematic review. Annals of Operations Research, 223(1), 53-79. http://dx.doi.org/10.1007/s10479-0141581-y.

Balcik, B., Beamon, B., \& Smilowitz, K. (2008). Last mile distribution in humanitarian relief. Journal of Intelligent Transport Systems, 12(2), 51-63. http://dx.doi.org/10.1080/15472450802023329.

Bandeira, R. A. M., Campos, V. B. G., \& De Paula, A. F. B. (2011). Uma visão logística de atendimento à população atingida. In Anais do XXV ANPET - Congresso de Pesquisa e Ensino em Transportes. Brasil: ANPET.

Barbarosoğlu, G., \& Arda, Y. (2004). A two-stage stochastic programming framework for transportation planning in disaster response. The Journal of the Operational Research Society, 55(1), 43-53. http://dx.doi.org/10.1057/palgrave.jors.2601652.

Barbarosoğlu, G., Özdamar, L., \& Çevik, A. (2002). An interactive approach for hierarquical analysis of helicopter logistics in disaster relief operations. European Journal of Operational Research, 140(1), 118-133. http://dx.doi.org/10.1016/S0377-2217(01)00222-3.

Battini, D., Peretti, U., Persona, A., \& Sgarbossa, F. (2014). Application of humanitarian last mile distribution model. Journal of Humanitarian Logistics and Supply Chain Management, 4(1), 131-148. http://dx.doi.org/10.1108/JHLSCM-01-2013-0001.

Berkoune, D., Renaud, J., Rekik, M., \& Ruiz, A. (2012). Transportation in disaster response operations. Socio-Economic Planning Sciences, 46(1), 23-32. http://dx.doi.org/10.1016/j.seps.2011.05.002.

Bisschop, J. J. (2012). AIMMS (3rd ed.). Netherlands: Paragon Decision Technology.

Clementson, T., \& Fisher, C. (2011). Analysis of U.S. military helicopter operations in support of humanitarian assistance and disaster relief. Monterey: Naval Postgraduate School. 
De Angelis, V., Mecoli, M., Nikoi, C., \& Storchi, G. (2007). Multiperiod integrated routing and scheduling of World Food Programme cargo planes in Angola. Computers \& Operations Research, 34(6), 1601-1615. http://dx.doi.org/10.1016/j.cor.2005.07.012.

Guha-Sapir, D., Kirsch, T., Dooling, S., \& Sirois, A. (2011). Independent review of the U. S. Government Response to the Haiti Earthquake. Washington: USAID.

Haghani, A., \& Oh, S. C. (1996). Formulation and solution of a multi-commodity, multi-modal network-ow model for disaster relief operations. Transportation Research Part A, Policy and Practice, 30(3), 231-250. http://dx.doi.org/10.1016/0965-8564(95)00020-8.

Holguín-Veras, J., Jaller, M., Van Wassenhove, L. N., Pérez, N., \& Wach-Tendorf, T. (2012). On the unique features of post-disaster humanitarian logistics. Journal of Operations Management, 30(7-8), 494-506. http://dx.doi.org/10.1016/j.jom.2012.08.003.

International Fedration of Red Cross and Red Crescent Societies - IFRC. (2008). Introduction to the guidelines fot the domestic facilitation and regulation of intern. Disaster Relief and Initial Recovery Assistance. Geneva: FRC.

Ignácio, A. A. V., \& Ferreira, V. J. M., Fo. (2004). O uso de software de modelagem AIMMS na solução de problemas de programação matemática. Pesquisa Operacional, 24(1), 197-210. http://dx.doi.org/10.1590/S0101-74382004000100011.

Kovács, G., \& Spens, K. M. (2012). Relief supply chain management for disasters: humanitarian aid and emergency logistics. Hershey: IGI Global. http://dx.doi.org/10.4018/978-1-60960-8248.

Liu, Y., Lei, H., Zhang, D., \& Wu, Z. (2018). Robust optimization for relief logistics planning under uncertainties in demand and transportation time. Applied Mathematical Modelling, 55, 262280. http://dx.doi.org/10.1016/j.apm.2017.10.041.

Najafi, M., Eshghi, K., \& Dullaert, W. (2013). A multi-objective robust optimization model for logistics planning in the earthquake response phase. Transportation Research Part E, Logistics and Transportation Review, 49(1), 217-249. http://dx.doi.org/10.1016/j.tre.2012.09.001.

North Atlantic Treaty Organization - OTAN. (2008). Computer based decision support toll for helicopter mission planning in disaster relief and military operations (pp. 1-298). Brussels: Research and Technology Organization.

Özdamar, L. (2011). Planning helicopter logistics in disaster relief. OR-Spektrum, 33(3), 655-672. http://dx.doi.org/10.1007/s00291-011-0259-y.

Özdamar, L., \& Demir, O. (2012). A hierarchical clustering and routing procedure for large scale disaster relief logistics planning. Transportation Research Part E: Logistics and Transportation Review, 48(3), 591-602. http://dx.doi.org/10.1016/j.tre.2011.11.003.

Özdamar, L., Ekinci, E., \& Küçükyazici, B. (2004). Emergency logistics planning in natural disasters. Annals of Operations Research, 129(1-4), 217-245. http://dx.doi.org/10.1023/B:ANOR.0000030690.27939.39.

Quarantelli, E. L. (2000). Emergencies, disaster and catastrophes are diferent phenomena (pp. 682-688). Newark, DE: Disaster Research Center.

Rivera, J. C., Afsar, H. M., \& Prins, C. (2015). A multistart iterated local search for the multitrip cumulative capacitated vehicle routing problem. Computational Optimization and Applications, 61(1), 159-187. http://dx.doi.org/10.1007/s10589-014-9713-5.

Thomas, A. S. (2003). Humanitarian logistics: enabling disaster response. San Francisco: Fritz Institute.

Thomé, A. M., Scavarda, L. F., \& Scavarda, A. J. (2016). Conducting systematic literature review in operations management. Production Planning and Control, 27(5), 408-420.

http://dx.doi.org/10.1080/09537287.2015.1129464. 
Planning the use of helicopters...

Xavier, I. R., Bandeira, R. A. D. M., \& Bandeira, A. D. P. F. (2015). Revisão do emprego de helicópteros em desastres naturais. In Anais do XXIX Congresso Nacional de Ensino e Pesquisa em Transporte da ANPET (pp. 450-461). Brasil: ANPET.

Yi, W. E., \& Özdamar, L. (2007). A dynamic logistics coordination model for evacuation and support in disaster response activities. European Journal of Operational Research, 179(3), 1177-1193. http://dx.doi.org/10.1016/j.ejor.2005.03.077. 